\title{
33
}

\section{Fußball (Mittelworträtsel)}

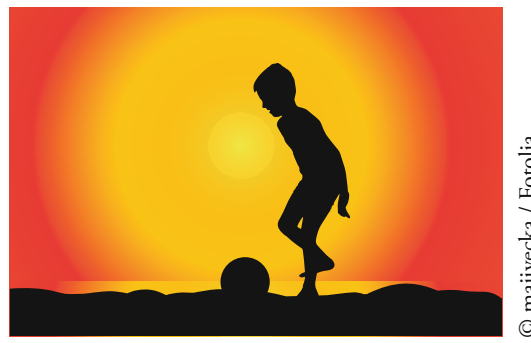

Suche in jeder Zeile das Wort, welches man links anfügen und rechts voransetzen kann, zum Beispiel FUSSBALL - LEDER - HAUT (s. u.). Die Buchstaben in den acht vorgegebenen Boxen ergeben - von oben nach unten gelesen - das Lösungswort.

Tipp In jeder Zeile findet sich etwas, das mit Fußball zu tun hat.

\begin{tabular}{cll} 
RHESUS & HITZE \\
\hline GREIF & SPIEL \\
\hline WILD & STEIGER \\
\hline ELF & GESENK \\
\hline FUSSBALL & HAUT \\
DEUTSCH & SCHILDKRÖTEN \\
\hline K.O.- & WETTE
\end{tabular}

Lösung:

(C) Springer-Verlag Berlin Heidelberg 2016

C. Reinbold, Fetthenne, Moderlieschen, Warzenbeißer,

DOI 10.1007/978-3-662-52817-4_33 